\title{
Dielectric behaviour of erbium substituted Mn-Zn ferrites
}

\author{
D RAVINDER* and K VIJAYA KUMAR \\ Department of Physics, Osmania University, Hyderabad 500 007, India
}

MS received 17 October 2000; revised 25 June 2001

\begin{abstract}
Dielectric properties such as dielectric constant $\left(\varepsilon^{\prime}\right)$ and dielectric loss tangent $(\tan \delta)$ of mixed $\mathrm{Mn}-\mathrm{Zn}$-Er ferrites having the compositional formula $\mathrm{Mn}_{0.58} \mathrm{Zn}_{0.37} \mathrm{Fe}_{2 \cdot 05-x} \mathrm{Er}_{x} \mathrm{O}_{4}$ (where $x=0 \cdot 2,0 \cdot 4,0 \cdot 6,0 \cdot 8$ and 1.0) were measured at room temperature in the frequency range 1-13 $\mathrm{MHz}$ using a $\mathrm{HP} 4192 \mathrm{~A}$ impedance analyser. Plots of dielectric constant $\left(\varepsilon^{\prime}\right)$ vs frequency show a normal dielectric behaviour of spinel ferrites. The frequency dependence of dielectric loss tangent $(\tan \delta)$ was found to be abnormal, giving a peak at certain frequency for all mixed Mn-Zn-Er ferrites. A qualitative explanation is given for the composition and frequency dependence of the dielectric constant and dielectric loss tangent. Plots of dielectric constant vs temperature have shown a transition near the Curie temperature for all the samples of $\mathrm{Mn}-\mathrm{Zn}$-Er ferrites. However, $\mathrm{Mn}_{0.58} \mathrm{Zn}_{0.37} \mathrm{Er}_{1.0} \mathrm{Fe}_{1.05} \mathrm{O}_{4}$ does not show a transition. On the basis of these results an explanation for the dielectric mechanism in Mn-Zn-Er ferrites is suggested.
\end{abstract}

Keywords. Dielectric constant; dielectric loss tangent; Mn-Zn-Er ferrites; electrical resistivity.

\section{Introduction}

The dependence of dielectric properties of $\mathrm{Li}-\mathrm{Mg}-\mathrm{Zn}$ ferrites as a function of frequency, composition and temperature has been studied (Shaikh et al 1999). The dielectric behaviour of the $\mathrm{Ni}-\mathrm{Zn}$ (where $0 \leq x \leq 1$ ) as a function of frequency, composition and temperature was reported (Abdun 1999). The dielectric behaviour of the $\mathrm{Ba}-\mathrm{Ni}-\mathrm{Zn}$ ferrites also as a function of temperature and frequency was reported (Elata et al 1999). The dielectric properties of $\mathrm{Ni}-\mathrm{Zn}$ ferrites as a function of sintering temperature, sintering time and frequency have been investigated (Rao and Rao 1997). A strong correlation between conduction mechanism and the dielectric behaviour of ferrites has been reported (Iwauchi 1971). The dielectric properties of $\mathrm{Mg}-\mathrm{Zn}$ ferrites were investigated (Ravinder and Lata 1999). With a view to the understanding of dielectric phenomena in mixed $\mathrm{Mn}-\mathrm{Zn}-\mathrm{Er}$ ferrites, a systematic study of dielectric properties as a function of frequency, composition and temperature was undertaken and the results of the study are presented in this paper.

\section{Experimental}

Polycrystalline mixed $\mathrm{Mn}-\mathrm{Zn}-\mathrm{Er}$ ferrites having the chemical formula $\mathrm{Mn}_{0.58} \mathrm{Zn}_{0.37} \mathrm{Fe}_{2 \cdot 05-x} \mathrm{Er}_{x} \mathrm{O}_{4}$ (where $x=0.2$, $0.4,0.6,0.8$ and 1.0 ) were prepared by a conventional double sintering ceramic method. X-ray diffractometer studies of the samples using $\mathrm{CuK}_{\alpha}$ radiation of Rigaku

\footnotetext{
*Author for correspondence
}

DMAX II X-ray Diffractometer confirmed the spinel formation. The dielectric measurements were made in the frequency range $1-13 \mathrm{MHz}$ using impedance analyser (Model HP4192 A of Hewlett-Packard). The value of the dielectric constant $\left(\varepsilon^{\prime}\right)$ of the ferrite sample is calculated using the formula

$$
\varepsilon^{\prime}=\frac{C \times t}{\varepsilon_{0} A},
$$

where $\varepsilon_{0}$ is an electrical constant equal to $8.854 \times 10^{-2}$ $\mathrm{pF} / \mathrm{cm}, C$ the capacitance of the specimen in $\mathrm{cm}, t$ the thickness of the specimen in $\mathrm{cm}$ and $A$ the area of the specimen in sq.cm. The complex dielectric constant $\left(\varepsilon^{\prime \prime}\right)$ of the ferrite sample is given by

$$
\varepsilon^{\prime \prime}=\varepsilon^{\prime} \tan \delta
$$

The Curie temperature, $T_{\mathrm{c}}(K)$ of the samples was determined by the gravity method.

\section{Results and discussion}

\subsection{Composition dependence of dielectric behaviour}

The room temperature values of the dielectric constant $\left(\varepsilon^{\prime}\right)$, dielectric loss tangent $(\tan \delta)$ and complex dielectric constant $\left(\varepsilon^{\prime \prime}\right)$ of mixed $\mathrm{Mn}-\mathrm{Zn}$-Er ferrites as derived from the experiments are given in table 1 . The values of electrical conductivity $(\sigma)$ and $\mathrm{Fe}^{2+}$ concentration are also included in the table to facilitate discussion. It can be seen from the table that the $\varepsilon^{\prime}$, $\tan \delta$ and $\varepsilon^{\prime \prime}$ of the mixed 
Table 1. Composition dependence of room temperature dielectric data for erbium substituted $\mathrm{Mn}-\mathrm{Zn}-\mathrm{Er}$ ferrites at $1 \mathrm{MHz}$.

\begin{tabular}{lcccccc}
\hline $\begin{array}{l}\text { Sample } \\
\text { no. }\end{array}$ & Ferrite composition & $\varepsilon^{\prime}$ & $\tan \delta$ & $\varepsilon^{\prime \prime}$ & $\begin{array}{c}\sigma \\
\left(\Omega^{-1} \cdot \mathrm{cm}^{-1}\right)\end{array}$ & $\begin{array}{c}\mathrm{Fe}^{2+} \text { composition } \\
(\%)\end{array}$ \\
\hline 1. & $\mathrm{Mn}_{0.58} \mathrm{Zn}_{0.37} \mathrm{Er}_{0.2} \mathrm{Fe}_{1.85} \mathrm{O}_{4}$ & 276 & 0.32 & 88.32 & $1.58 \times 10^{-7}$ & 1.24 \\
2. & $\mathrm{Mn}_{0.58} \mathrm{Zn}_{0.37} \mathrm{Er}_{0.4} \mathrm{Fe}_{1.65} \mathrm{O}_{4}$ & 124 & $0 \cdot 16$ & 19.84 & $5.86 \times 10^{-9}$ & 0.92 \\
3. & $\mathrm{Mn}_{0.58} \mathrm{Zn}_{0.37} \mathrm{Er}_{0.6} \mathrm{Fe}_{1.45} \mathrm{O}_{4}$ & 224 & 0.24 & 53.76 & $5.05 \times 10^{-8}$ & 1.18 \\
4. & $\mathrm{Mn}_{0.58} \mathrm{Zn}_{0.37} \mathrm{Er}_{0.8} \mathrm{Fe}_{1.25} \mathrm{O}_{4}$ & 338 & 0.42 & 141.96 & $8.56 \times 10^{-7}$ & 1.32 \\
5. & $\mathrm{Mn}_{0.58} \mathrm{Zn}_{0.37} \mathrm{Er}_{1.0} \mathrm{Fe}_{1.05} \mathrm{O}_{4}$ & 446 & 0.52 & 231.92 & $2.00 \times 10^{-5}$ & 1.68 \\
\hline
\end{tabular}

Mn-Zn-Er ferrites decreases with decreasing concentration of $\mathrm{Fe}^{2+}$ ions till the concentration $(x)$ of erbium is equal to $0 \cdot 4$. Beyond $x=0 \cdot 4$, these parameters show an increase with increase of erbium content. Among all the ferrites, the specimen with the composition $\mathrm{Mn}_{0.58} \mathrm{Zn}_{0.37}$ $\mathrm{Er}_{1 \cdot 0} \mathrm{Fe}_{1 \cdot 05} \mathrm{O}_{4}$ exhibits the highest value of dielectric constant.

Further, it can be seen that $\mathrm{Mn}_{0.58} \mathrm{Zn}_{0.37} \mathrm{Er}_{0.4} \mathrm{Fe}_{1 \cdot 65} \mathrm{O}_{4}$, which has the lowest $\mathrm{Fe}^{2+}$ concentration, exhibits the lowest dielectric constant, the lowest dielectric loss tangent and the lowest complex dielectric constant. The dielectric studies of $\mathrm{Gd}^{3+}$ substituted copper-cadmium ferrites as a function of composition and frequency was investigated by Kolekar et al (1995). Ramana Reddy et al (1999) have investigated the dielectric behaviour of $\mathrm{Ni}-\mathrm{Zn}$ ferrites as a function of temperature and frequency. Iwauchi (1971) reported a strong correlation between the conduction mechanism and the dielectric behaviour of the ferrites starting with the conjecture that the mechanism of the polarization process in ferrites is similar to that of the conduction process (Rabinkin and Novikova 1960). They observed that the electronic exchange between $\mathrm{Fe}^{2+} \Leftrightarrow \mathrm{Fe}^{3+}$ results in local displacements which determine the polarization behaviour of the ferrites.

A similar explanation is proposed for the composition dependence of the dielectric constants of the ferrites under this investigation. It can be observed from table 1 that the composition, $\mathrm{Mn}_{0.58} \mathrm{Zn}_{0.37} \mathrm{Er}_{1.0} \mathrm{Fe}_{1.05} \mathrm{O}_{4}$, has the maximum divalent iron ion concentration among all the mixed Mn-Zn-Er ferrites. Correspondingly the dielectric constant for this specimen has a maximum value of 446 at $1 \mathrm{MHz}$. This high value can be explained on the basis of the fact that it has maximum number of ferrous ions which involve in the phenomenon of exchange $\mathrm{Fe}^{2+} \Leftrightarrow \mathrm{Fe}^{3+}$ giving rise to maximum dielectric polarization. Table 1 reveals that the variation of the dielectric constant of $\mathrm{Mn}-\mathrm{Zn}-\mathrm{Er}$ ferrites runs parallel to the variation of available ferrous ions on octahedral sites. It is significant to note that $\mathrm{Mn}_{0.58} \mathrm{Zn}_{0.37} \mathrm{Er}_{0.4} \mathrm{Fe}_{1 \cdot 65} \mathrm{O}_{4}$ which has the lowest ferrous ion concentration also possesses the lowest dielectric constant. It is also pertinent to mention that the variation of electrical conductivity with composition (table 1)

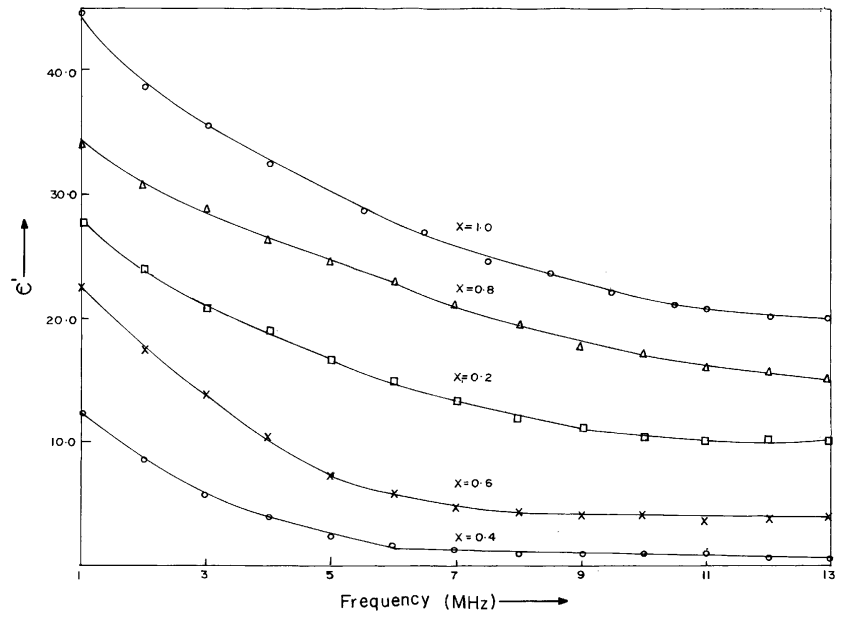

Figure 1. Plot of dielectric constant $\left(\varepsilon^{\prime}\right)$ against frequency for $\mathrm{Mn}_{0.58} \mathrm{Zn}_{0.37} \mathrm{Er}_{x} \mathrm{Fe}_{2 \cdot 05-x} \mathrm{O}_{4}$ (where $x=0 \cdot 2,0 \cdot 4,0 \cdot 6,0 \cdot 8$ and 1.0).

parallels the variation of ferrous ion concentration (Ravinder 1988). Thus, it is the number of ferrous ions on the octahedral sites that play a dominant role in the processes of conduction as well as dielectric polarization. This result is in agreement with the assumption made earlier (Rabinkin and Novikova 1960).

\subsection{Frequency dependence of dielectric constant $\left(\varepsilon^{\prime}\right)$}

The variations of dielectric constant as a function of frequency for mixed $\mathrm{Mn}-\mathrm{Zn}-\mathrm{Er}$ ferrites with different compositions is shown in figure 1 . It can be seen from the figure that the value of dielectric constant decreases continuously with increasing frequency. The dispersion of dielectric constant is maximum for $\mathrm{Mn}_{0.58} \mathrm{Zn}_{0.37}$ $\mathrm{Er}_{1 \cdot 0} \mathrm{Fe}_{1 \cdot 05} \mathrm{O}_{4}$.

The decrease of dielectric constant with increase of frequency as observed in the case of mixed $\mathrm{Mn}-\mathrm{Zn}-\mathrm{Er}$ ferrites is a normal dielectric behaviour. This normal dielectric behaviour was also observed by several other investigators (Chandra Prakash and Bajal 1985; Ravinder 1993; Ramana Reddy et al 1999). The normal dielectric behaviour of spinel ferrites was also explained by Rezlescu and Rezlescu (1974). Following their work, the 
dependence of the dispersion of the dielectric constant on composition can be explained. The observation that $\mathrm{Mn}_{0.58} \mathrm{Zn}_{0.37} \mathrm{Er}_{1.0} \mathrm{Fe}_{1.05} \mathrm{O}_{4}$ shows a maximum dielectric dispersion among the mixed $\mathrm{Mn}-\mathrm{Zn}-\mathrm{Er}$ ferrites may be explained on the basis of the available ferrous ions on octahedral sites. In the case of $\mathrm{Mn}_{0.58} \mathrm{Zn}_{0.37} \mathrm{Er}_{1 \cdot 0} \mathrm{Fe}_{1.05} \mathrm{O}_{4}$ the ferrous ion content is higher than in other mixed $\mathrm{Mn}-\mathrm{Zn}$-Er ferrites. As a consequence, it is possible for these ions to be polarized to the maximum possible extent. Further, as the frequency of the externally applied electric field increases gradually, and though the same number of ferrous ions is present in the ferrite material, the dielectric constant $\left(\varepsilon^{\prime}\right)$ decreases from 446 at $1 \mathrm{MHz}$ to 200 at $13 \mathrm{MHz}$. This reduction occurs because beyond a certain frequency of the externally applied electric field, the electronic exchange between ferrous and ferric ions i.e. $\mathrm{Fe}^{2+} \Leftrightarrow \mathrm{Fe}^{3+}$ can not follow the alternating field. The variation of the dispersion of $\varepsilon^{\prime}$ with composition can also be explained on the same lines as above.

\subsection{Variation of dielectric loss tangent ( $\tan \delta)$ with frequency}

Figure 2 shows the variation of $\tan \delta$ with frequency for mixed $\mathrm{Mn}-\mathrm{Zn}-\mathrm{Er}$ ferrites. It can be seen from the figures

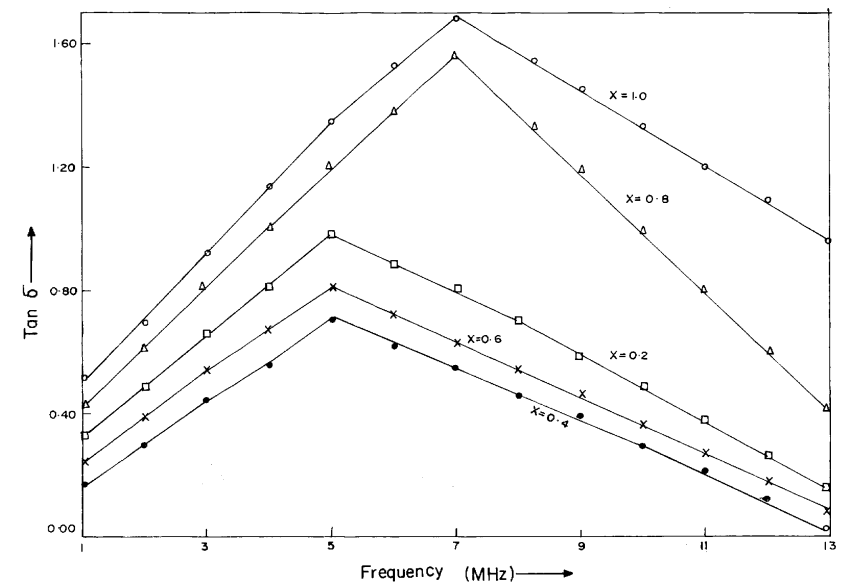

Figure 2. Plot of dielectric loss tangent $(\tan \delta)$ against frequency for $\mathrm{Mn}_{0.58} \mathrm{Zn}_{0.37} \mathrm{Er}_{x} \mathrm{Fe}_{2 \cdot 05-x} \mathrm{O}_{4}$ (where $x=0 \cdot 2,0 \cdot 4,0 \cdot 6$, $0 \cdot 8$ and $1 \cdot 0)$. that in the case of $\mathrm{Mn}_{0.58} \mathrm{Zn}_{0.37} \mathrm{Er}_{0.2} \mathrm{Fe}_{1 \cdot 85} \mathrm{O}_{4}, \mathrm{Mn}_{0.58} \mathrm{Zn}_{0.37}$ $\mathrm{Er}_{0.4} \mathrm{Fe}_{1.65} \mathrm{O}_{4}$ and $\mathrm{Mn}_{0.58} \mathrm{Zn}_{0.37} \mathrm{Er}_{0.6} \mathrm{Fe}_{1.45} \mathrm{O}_{4}$, tan $\delta$ shows a maximum at $5 \mathrm{MHz}$ and for $\mathrm{Mn}_{0.58} \mathrm{Zn}_{0.37} \mathrm{Er}_{0.8} \mathrm{Fe}_{1.25} \mathrm{O}_{4}$ and $\mathrm{Mn}_{0.58} \mathrm{Zn}_{0.37} \mathrm{Er}_{1.0} \mathrm{Fe}_{1.05} \mathrm{O}_{4}$, tan $\delta$ shows a maximum at $7 \mathrm{MHz}$. A qualitative explanation can be given for the occurrence of the maximum in the $\tan \delta$ vs frequency curves in the case of mixed $\mathrm{Mn}-\mathrm{Zn}-\mathrm{Er}$ ferrites. As pointed out by Iwauchi (1971), there is a strong correlation between the conduction mechanism and the dielectric behaviour of ferrites. The conduction mechanism in $n$-type ferrites is considered as due to hopping of electrons between $\mathrm{Fe}^{2+}$ and $\mathrm{Fe}^{3+}$. As such, when the hopping frequency is nearly equal to that of the frequency of externally applied electric field, a maximum of loss tangent may be observed. Thus, in the case of $\mathrm{Mn}_{0.58} \mathrm{Zn}_{0.37} \mathrm{Er}_{0.2} \mathrm{Fe}_{1.85} \mathrm{O}_{4}, \mathrm{Mn}_{0.58} \mathrm{Zn}_{0.37} \mathrm{Er}_{0.4} \mathrm{Fe}_{1.65} \mathrm{O}_{4}, \mathrm{Mn}_{0.58}$ $\mathrm{Zn}_{0.37} \mathrm{Er}_{0.6} \mathrm{Fe}_{1.45} \mathrm{O}_{4}, \mathrm{Mn}_{0.58} \mathrm{Zn}_{0.37} \mathrm{Er}_{0.8} \mathrm{Fe}_{1.25} \mathrm{O}_{4}$ and $\mathrm{Mn}_{0.58} \mathrm{Zn}_{0.37}$ $\mathrm{Er}_{1.0} \mathrm{Fe}_{1.05} \mathrm{O}_{4}$, the hopping frequencies are of the appropriate magnitude, to observe a loss maximum at $5 \mathrm{MHz}$ and $7 \mathrm{MHz}$, respectively.

The condition for observing a maximum in the dielectric losses of a dielectric material is given by

$$
w \tau=1,
$$

where $w$ is the $2 \pi f_{\max }$ and $\tau$ the relaxation time. Now the relaxation time $\tau$ is related to the jumping probability per unit time $p$, by an equation

$$
\begin{array}{cl}
\tau=\frac{1}{2} p & \text { or } \\
f_{\max } \propto p . &
\end{array}
$$

Equation (4) shows that $f_{\max }$ is proportional to the jumping or hopping probability. Now an increase of $f_{\max }$ with increasing erbium content indicates that the hopping or jumping probability per unit time increases with erbium content.

\subsection{Relationship between dielectric constant $\left(\varepsilon^{\prime}\right)$ and resistivity $(\rho)$}

The computed values of resistivity $(\rho), \sqrt{ } \rho$ and $\varepsilon^{\prime} \sqrt{ } \rho$ are given in table 2 along with the value of $\varepsilon^{\prime}$ and $\tan \delta$. It can be seen from the table that $\varepsilon^{\prime}$ is approximately inversely proportional to the square root of resistivity. As such the

\begin{tabular}{|c|c|c|c|c|c|c|}
\hline $\begin{array}{l}\text { Sample } \\
\text { no. }\end{array}$ & Ferrite composition & $\varepsilon^{\prime}$ & $\tan \delta$ & $\begin{array}{c}\rho \\
(\Omega \cdot \mathrm{cm})\end{array}$ & $\begin{array}{c}\sqrt{ } \rho \\
\left(\Omega^{1 / 2} \cdot \mathrm{cm}^{1 / 2}\right)\end{array}$ & $\begin{array}{c}\mathcal{E}^{\prime} \sqrt{ } \rho \\
\left(\Omega^{1 / 2} \cdot \mathrm{cm}^{1 / 2}\right)\end{array}$ \\
\hline 1. & $\mathrm{Mn}_{0.58} \mathrm{Zn}_{0.37} \mathrm{Er}_{0.2} \mathrm{Fe}_{1.85} \mathrm{O}_{4}$ & 276 & $0 \cdot 32$ & $6.33 \times 10^{6}$ & $2.52 \times 10^{3}$ & $6.95 \times 10^{5}$ \\
\hline 2. & $\mathrm{Mn}_{0.58} \mathrm{Zn}_{0.37} \mathrm{Er}_{0.4} \mathrm{Fe}_{1.65} \mathrm{O}_{4}$ & 124 & $0 \cdot 16$ & $17.06 \times 10^{7}$ & $1.31 \times 10^{4}$ & $16 \cdot 24 \times 10^{5}$ \\
\hline 3. & $\mathrm{Mn}_{0.58} \mathrm{Zn}_{0.37} \mathrm{Er}_{0.6} \mathrm{Fe}_{1.45} \mathrm{O}_{4}$ & 224 & $0 \cdot 24$ & $1.98 \times 10^{7}$ & $0.44 \times 10^{4}$ & $9.85 \times 10^{5}$ \\
\hline 4. & $\mathrm{Mn}_{0.58} \mathrm{Zn}_{0.37} \mathrm{Er}_{0.8} \mathrm{Fe}_{1.25} \mathrm{O}_{4}$ & 338 & 0.42 & $1.16 \times 10^{6}$ & $1.08 \times 10^{3}$ & $3.65 \times 10^{5}$ \\
\hline 5. & $\mathrm{Mn}_{0.58} \mathrm{Zn}_{0.37} \mathrm{Er}_{1.0} \mathrm{Fe}_{1.05} \mathrm{O}_{4}$ & 446 & 0.52 & $0.2 \times 10^{5}$ & $1.41 \times 10^{2}$ & $0.63 \times 10^{5}$ \\
\hline
\end{tabular}

Table 2. Variation of dielectric constant $\left(\varepsilon^{\prime}\right), \tan \delta$ and resistivity $(\rho)$ in the case of mixed $\mathrm{Mn}-\mathrm{Zn}-\mathrm{Er}$ ferrites. 


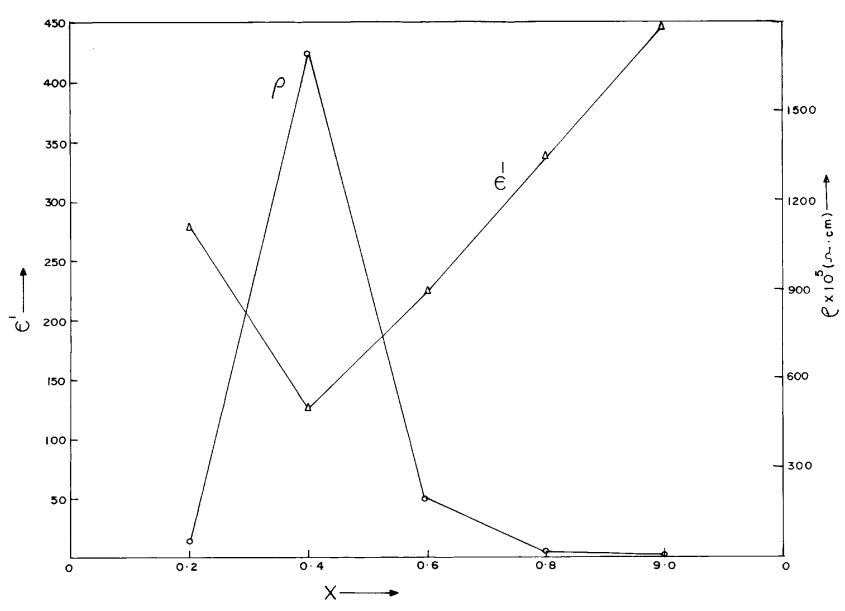

Figure 3. Plot of dielectric constant and resistivity ( $\rho$ ) vs erbium content for mixed $\mathrm{Mn}-\mathrm{Zn}-\mathrm{Er}$ ferrites.

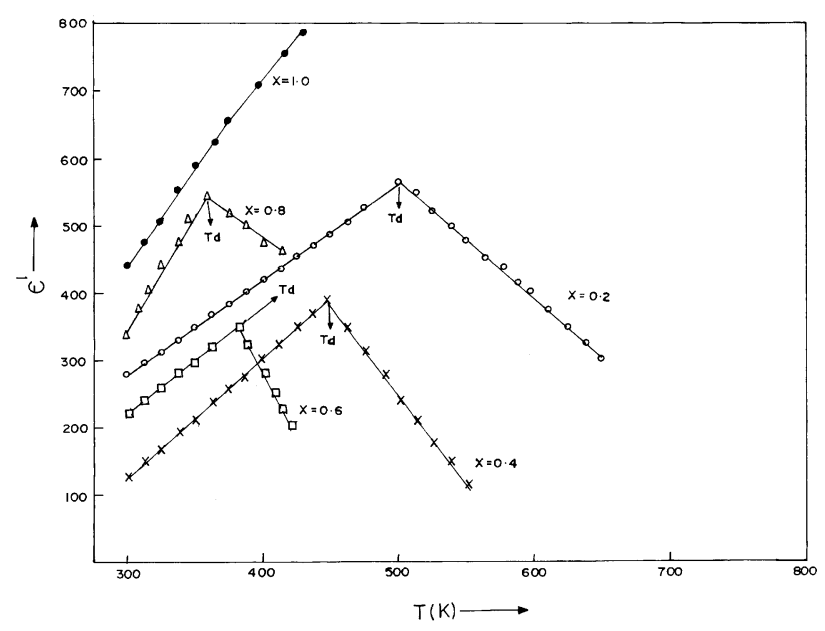

Figure 4. Variation of dielectric constant with temperature at $1 \mathrm{MHz}$ for mixed $\mathrm{Mn}-\mathrm{Zn}-\mathrm{Er}$ ferrites.

product $\varepsilon^{\prime} \sqrt{ } \rho$ remains nearly constant as shown in table 2 . A similar relationship between $\varepsilon^{\prime}$ and $\rho \frac{1}{2}$ was found by Koops (1951) and Venugopal Reddy and Seshagiri Rao (1985) in the case of $\mathrm{Ni}-\mathrm{Zn}$ and $\mathrm{Mn}-\mathrm{Mg}$ ferrites. Hudson (1968) has shown that the dielectric losses in ferrites are generally reflected in the resistivity measurements, materials with low resistivity exhibiting high dielectric losses and vice versa. Table 2 shows that this result holds good in the case of mixed $\mathrm{Mn}-\mathrm{Zn}-\mathrm{Er}$ ferrites too. Figure 3 shows that the plot of dielectric constant $\left(\varepsilon^{\prime}\right)$ vs the erbium content $(X)$ is an inverse image of that of the resistivity vs erbium content. This is a confirmation of the correlation between dielectric constant and resistivity proposed earlier (Rabinkin and Novikova 1960).

\subsection{Variation of dielectric constant $\left(\varepsilon^{\prime}\right)$ with temperature}

Figure 4 shows the variation of dielectric constant at $1 \mathrm{MHz}$ with temperature for mixed $\mathrm{Mn}-\mathrm{Zn}-\mathrm{Er}$ ferrites.
Table 3. Curie temperatures $\left(T_{\mathrm{c}}\right)$ and dielectric transition temperatures $\left(T_{\mathrm{d}}\right)$ for mixed $\mathrm{Mn}-\mathrm{Zn}-\mathrm{Er}$ ferrites.

\begin{tabular}{lccc}
\hline $\begin{array}{l}\text { Sample } \\
\text { no. }\end{array}$ & $X$ & $T_{\mathrm{c}}(K)$ & $T_{\mathrm{d}}(K)$ \\
\hline 1. & $0 \cdot 2$ & 502 & 500 \\
2. & $0 \cdot 4$ & 442 & 445 \\
3. & $0 \cdot 6$ & 380 & 382 \\
4. & $0 \cdot 8$ & 369 & 370 \\
5. & $1 \cdot 0$ & - & - \\
\hline
\end{tabular}

The dielectric constant increases gradually with increasing temperature up to a certain temperature, which is designated as the dielectric transition temperature, $T_{\mathrm{d}}$. However, beyond this temperature the values of dielectric constant for all the samples were found to decrease continuously. A similar temperature variation of the dielectric constant has been reported earlier (Olofa 1994; Yadav and Chowdhary 1994; Bera and Chowdhary 1995). The value of $T_{\mathrm{d}}(K)$ for each composition is given in table 3 . The Curie temperature values, $T_{\mathrm{c}}(K)$ determined by the gravity method are also included in the table for the purpose of comparison. It can be seen from table 3 that the values of $T_{\mathrm{d}}(K)$ and $T_{\mathrm{c}}(K)$ are in good agreement, thereby indicating that the change in the behaviour of the dielectric constant with temperature may be due to a magnetic transition, where the material becomes paramagnetic. Similar agreement of $T_{\mathrm{c}}(K)$ and $T_{\mathrm{d}}(K)$ was also observed by Ramana Reddy et al (1999) in Co-Zn ferrites. No such dielectric transition was observed for the sample $\mathrm{Mn}_{0.58} \mathrm{Zn}_{0.37}$ $\mathrm{Er}_{1.0} \mathrm{Fe}_{1.05} \mathrm{O}_{4}$ which suggests that this ferrite is paramagnetic at room temperature.

\section{Acknowledgement}

The authors are grateful to the Department of Science and Technology (DST), New Delhi for the financial assistance.

\section{References}

Abdun A M 1999 J. Magn. Magn. Mater. 192121

Bera S and Chowdhary R N P 1995 Mater. Lett. 22197

Chandra Prakash and Bajal J S 1985 J. Less Common Metals 10751

Elata A M A, Ahmed M A, Elhiti M A and Nimr M K El 1999 J. Mater. Sci. Lett. 18563

Hudson A S 1968 Marconi Rev. 3743

Iwauchi K 1971 Jap. J. Appl. Phys. 101520

Kolekar C B, Kamble P N, Kulkarni S G and Vaingankar A S 1995 J. Mater. Sci. 305784

Koops C G 1951 Phys. Rev. 83121

Olofa S A 1994 J. Magn. Magn. Mater. 131103

Rabinkin L I and Novikova Z I 1960 Ferrites Minsk (in Russian) p. 146 
Ramana Reddy A V, Ranga Mohan G, Ravinder D and Boyanov B S 1999 J. Mater. Sci. 343169

Ranga Mohan G, Ravinder D, Ramana Reddy A V and Boyanov B S 1999 Mater. Letts 4039

Rao B P and Rao K H 1997 J. Mater. Sci. B32 6049

Ravinder D 1988 Electrical properties of lithium-zinc and lithium-cadmium ferrites, Ph.D. Thesis, Osmania University, Hyderabad
Ravinder D 1993 Phys. Status Solidi (a) 139 K69

Ravinder D and Latha K 1999 Mater. Letts 41247

Rezlescu N and Rezlescu E 1974 Phys. Status Solidi A23 575

Shaikh A M, Bellad S S and Chougule B K 1999 J. Magn. Magn. Mater. 195384

Venugopal Reddy P and Seshagiri Rao T 1985 J. Less Common Metals 10563

Yadav K L and Chowdhary R N P 1994 Mater. Lett. 1961 